\title{
PRISMA Kontrol Listesi 2020 Güncellemesi
}

\section{The PRISMA Checklist 2020 Update}

\author{
${ }^{1}$ Gülşah HÜR \\ ${ }^{1}$ Karabük Üniversitesi Sağlık Hizmetleri Meslek Yüksekokulu, Tıbbi Hizmetler ve Teknikler Bölümü, Karabük/Türkiye \\ Gülşah Hür: http://orcid.org/0000-0002-1905-4135
}

\section{ÖZ}

$\mathrm{Bu}$ mektup ile ülkemizdeki dergi editörleri, hakemler ve yazarlara yardımcı olabileceğini düşündüğ̈̈müz sistematik derleme ve meta-analiz raporlarının sunumunda uluslararası öneme sahip bir kılavuz olan Sistematik Derleme ve Meta-Analizler için Tercih Edilen Raporlama Öğeleri (Preferred Reporting Items for Systematic Reviews and Meta-Analyses=PRISMA) kontrol listesindeki güncelleme ve değişiklikler konusundaki bilginin paylaşılması amaçlanmıștır.

Anahtar Kelimeler: PRISMA kontrol listesi, güncelleme, 2020

\begin{abstract}
With this letter, it is aimed to share the information about the updates and changes in the Preferred Reporting Items for Systematic Reviews and Meta-Analyses (PRISMA) checklist that we think may help the journal editors, reviewers and authors in our country. It is an internationally important guide in the presentation of systematic reviews and meta-analysis reports.
\end{abstract}

Keywords: PRISMA checklist, update, 2020
Sorumlu Yazar / Corresponding Author:

Gülşah HÜR

Karabük Üniversitesi Sağlık Hizmetleri Meslek Yüksekokulu, Yenimahalle Mah. Prof. Metin Sözen Cad. No: 4/1 78600 Safranbolu/KARABÜK

Tel: +03704188700

Email: gulsahhur@karabuk.edu.tr
Yayın Bilgisi / Article Info:

Gönderi Tarihi/ Received: 27/09/2021

Kabul Tarihi/ Accepted: 04/10/2021

Online Yayın Tarihi/ Published: 01/12/2021

Atıf/ Cited: Hür, G. PRISMA Kontrol Listesi 2020 Güncellemesi. Online Türk Sağllk Bilimleri Dergisi 2021;6(4):603-605. doi:10.26453/ otjhs. 1001606

Sayın Editör,

Bu mektup Çınar ${ }^{1}$ tarafından yazılmış "İyi Bir Sistematik Derleme Nasıl Yazılmalı?” başlıklı makaleden yola çıkarak PRISMA kontrol listesindeki güncelleme ve değişiklikler konusundaki bilginin paylaşılması ihtiyacı doğmuştur. PRISMA, ülkemizdeki dergi editörleri, hakemler ve yazarlara yardımcı olabileceğini düşündüğümüz sistematik derleme ve meta-analiz raporlarının sunumunda uluslararası öneme sahip bir k1lavuzdur.

PRISMA kontrol listesi, sistematik derleme ve metaanaliz çalışmalarının tanımlama, seçme, değerlendirme ve sentezi için hazırlanmış 27 maddeden oluşan bir raporlama kılavuzudur. ${ }^{2}$ Uluslararası literatürde sistematik derleme ve meta-analiz raporunun sunumunda önerilen bu kılavuz, raporun eksiksiz hazırlanmasında büyük öneme sahip olmakla birlikte araştırmacılar için yol gösterici niteliktedir. ${ }^{2,3} 2009$ yılında geliştirilen PRISMA kontrol listesi, 2020 y1lı itibariyle güncellenmiştir. ${ }^{2,4}$ Güncelleme, kontrol listeleri ve akış diyagramını içermektedir. ${ }^{2}$ Güncelleme ile PRISMA kontrol listesinin bazı bölümlerinde önemli değişiklikler yapılmıştır. Özet bölümü için ayrı bir tabloda özet kontrol listesine yer verilmiştir. ${ }^{2}$ Yapılan değişikliklerin tüm bilim çevresine duyuru- labilmesi için güncelleme çalışması uluslararası düzeyde beş farklı dergide (BMJ, International Journal of Surgery, Journal of Clinical Epidemiology, PLOS Medicine, Systematic Reviews) yayınlanmıştır., ${ }^{2,5-8}$ PRISMA 2020 kontrol listeleri, Çınar ve Hür tarafindan İngilizceden Türkçeye çevrilmiştir. ${ }^{9}$ Çeviri öncesi, araştırmacılardan mail yoluyla izin alınmış, çevirinin uygunluğu bir dil uzmanı ve birincil araştırmacılar tarafından değerlendirilmiştir. PRISMA 2020 kontrol listelerinin Türkçe çevirisi http:// www.prisma-statement.org/translations/translations bağlantısından yayınlanmıştır.

\section{PRISMA 2020 KONTROL LISTESINDE YER ALAN ÖNEMLİ DEĞİŞIKLIKKLER VE İLGİİ MADDELER}

Madde 2'de yer alan değişiklik: PRISMA 2020 kontrol listesine özetin raporlanması dâhil edilmiştir. "Özet" bölümünde yer alan bu madde için ayrı bir özet kontrol listesi sunulmuştur. Özel kontrol listesi; başlık, giriş, yöntemler, sonuçlar, tartışma ve diğer (finansman ve kayıt) bölümlerinin yer aldığı 12 maddeden oluşmaktadır. ${ }^{2-4}$

PRISMA 2020 özet kontrol listesi, 2013'te yayınlanan özetler için PRISMA bildiriminde bulunanlarla 
aynı maddeleri korur, ancak ifadelerin PRISMA 2020 bildirimiyle tutarlı hale getirilmesi için revize edilmiştir. Ayrıca yazarların sunumda ve sonuçları sentezlemek için kullandıkları yöntemleri belirtmelerini öneren yeni bir madde (madde 6) içermektedir. $^{2,10}$

Madde 7'de yer alan değişiklik: “Arama” bölümü, yazarların yalnızca en az bir veri tabanı için değil, tüm veri tabanları, kayıtlar ve aranan web siteleri için tam arama stratejileri sunmasını önermek için değiştirilmiştir. ${ }^{2-4}$

Madde 8'de yer alan değişiklik: Yöntemler bölümündeki 'Seçim süreci' alanı, her bir kaydı kaç gözden geçirenin taradığını ve bağımsız çalışıp çalışmadığını ve varsa süreçte kullanılan otomasyon araçlarının ayrıntılarını raporlamayı vurgulamak için değiştirilmiştir. ${ }^{2-4}$

Madde 10a'da yer alan değişiklik: "Veri maddeleri" alanına bir alt madde eklenmiştir. Yazarların, sonuçların nasıl tanımlandığını, hangi sonuçların arandığını ve dâhil edilen çalışmalardan sonuçları seçme yöntemlerini bildirmeleri önerilmektedir. ${ }^{2-4}$

Madde 13a-13f'de yer alan değişiklik: "Sentez yöntemleri" alanı altı alt maddeye bölünmüştür. Yazarlardan, her sentez için hangi çalışmaların uygun olduğuna karar vermek için kullanılan süreçler; verileri senteze hazırlamak için gerekli herhangi bir yöntem; bireysel çalışmaların ve sentezlerin sonuçlarını tablo haline getirmek veya görsel olarak görüntülemek için kullanılan yöntemler; sonuçları sentezlemek için kullanılan yöntemler; çalışma sonuçları arasındaki olası heterojenlik nedenlerini araştırmak için kullanılan herhangi bir yöntem (alt grup analizi, meta-regresyon gibi); ve sentezlenen sonuçların sağlamlığını değerlendirmek için kullanılan herhangi bir duyarlılık analizini açıklaması önerilmektedir. ${ }^{2-4}$

Madde 15 ve 22'de yer alan değişiklik: Yazarlara, bir sonuca yönelik kanıtlardaki kesinlik (veya güvenirlik) değerlendirmesinin yöntemlerini ve sonuçlarını bildiren yeni maddelerin eklenmesi önerilmektedir. $^{2-4}$

Madde 16b'de yer alan değişiklik: Sonuçlar bölümündeki "Çalışma seçimi”" alanına bir alt madde eklenmiştir. Yazarların dâhil etme kriterlerini karşılıyor gibi görünen ancak hariç tutulan çalışmaları belirtmeleri ve neden hariç tutulduklarını açıklamaları önerilmektedir. ${ }^{2-4}$

Madde 20a-20d'de yer alan değişiklik: Sonuçlar bölümündeki "Sentezin sonuçları" alanı dört alt maddeye bölünmüştür. Bu maddelerde, senteze katkıda bulunan çalışmaların özelliklerini ve yanlılık riskini kısaca özetleme; yürütülen tüm istatistiksel sentezlerin sonuçlarını sunma; çalışma sonuçları arasında olası heterojenlik nedenlerine ilişkin herhangi bir araştırmanın sonuçlarını sunma ve herhangi bir duyarlılık analizinin sonuçlarını sunma yer almaktadır. $^{2-4}$
Madde 24a-24c'de yer alan değişiklik: "Kayıt ve protokol" alanı kontrol listesinin "Yöntemler" bölümünün başlangıcından yeni bir "Diğer bilgi”" bölümüne taşınmıştır. Yazarların kayıt sırasında veya protokolde sağlanan bilgilerde yapılan değişiklikleri açıklamasını öneren bir alt madde eklenmiştir. ${ }^{2-4}$

Madde 26'de yer alan değişiklik: Yazarların çıkar çatışmalarını beyan etmelerini öneren yeni bir madde eklenmiştir. ${ }^{2-4}$

Madde 27'de yer alan değişiklik: Yazarlara, derlemede kullanılan verilerin, analitik kodun ve diğer materyallerin kamuya açık olup olmadığını ve varsa nerede bulunabileceklerini belirtmelerini öneren yeni bir madde eklenmiştir. ${ }^{2-4}$

Sonuç olarak, PRISMA 2020 güncellemesi ile Özetler için Kontrol Listesi'nde yer alan "madde 6" dâhil olmak üzere 13 maddede belirgin değişiklik yapıldığ1 görülmektedir. Bu değişiklikler yeni sistematik derleme ve meta-analiz çalışmalarında özellikle yöntem ve sentez bölümlerinin daha detaylı sunumuna ilişkin öneriler içermektedir. Sistematik derleme ve meta-analiz raporlarının sunumunda uluslararası öneme sahip bir k1lavuz olan PRISMA kontrol listelerindeki güncelleme ve değişiklikleri paylaştığımız bu mektubun ülkemizdeki dergi editörleri, hakemler ve yazarlara çalışmalarında yardımcı olmasını ümit ederim.

Saygilarımla.

Etik Komite Onayı: Editöre mektup yazısıdır. Etik kurul onayı gerekmez.

Çıkar Çatışması: Yazar çıkar çatışması bildirmemiştir.

Hakem Değerlendirmesi: Editoryal değerlendirme.

Teşekkür: PRISMA kontrol listelerinin Türkçeye çevrilmesinde ve bu editöre mektup yazısının planlanmasından yayınlanmasına kadar tüm aşamalarında bana sunduğu destek ve katkılardan dolayı değerli hocam, danışmanım Sayın Prof. Dr. Nursan ÇINAR' a teşekkürlerimi sunarım.

\section{KAYNAKLAR}

1. Çınar N. İyi bir sistematik derleme nasıl yazılma11? OTSBD. 2021;6(2):310-314.

2. Page MJ, McKenzie JE, Bossuyt PM, ve ark. The PRISMA 2020 statement: an updated guideline for reporting systematic reviews. BMJ. 2021;372 (71):1-9. doi:10.1136/bmj.n71

3. Karaçam Z. Sistematik derleme metodolojisi: Sistematik derleme hazırlamak için bir rehber. DEUHFED. 2013;6(1):26-33.

4. Moher D, Liberati A, Tetzlaff J, Altman DG; PRISMA Group. Preferred reporting items for systematic reviews and meta-analyses: the PRISMA statement. PLoS Med. 2009;6(7):1-6. doi:10.1371/journal.pmed.1000097

5. Page MJ, McKenzie JE, Bossuyt PM, ve ark. The 
PRISMA 2020 statement: an updated guideline for reporting systematic reviews. Int J Surg. 2021;88:105906. doi:10.1016/.ijsu.2021.105906

6. Page MJ, McKenzie JE, Bossuyt PM, ve ark. The PRISMA 2020 statement: an updated guideline for reporting systematic reviews. J Clin Epidemiol. 2021;134:178-189. doi:10.1016/ j.jclinepi.2021.03.001

7. Page MJ, McKenzie JE, Bossuyt PM, ve ark. The PRISMA 2020 statement: an updated guideline for reporting systematic reviews. PLoS Med. 2021;18(3):e1003583. doi:10.1371/ journal.pmed.1003583

8. Page MJ, McKenzie JE, Bossuyt PM, ve ark. The PRISMA 2020 statement: an updated guideline for reporting systematic reviews. Syst Rev. 2021;10:89. doi:10.1186/s13643-021-01626-4

9. PRISMA 2020 Kontrol Listesi (Çeviren: Çınar N, Hür G). http://prisma-statement.org/ Translations/Translations. Erişim tarihi 10 Haziran 2021.

10. Beller EM, Glasziou PP, Altman DG, ve ark. PRISMA for Abstracts: reporting systematic reviews in journal and conference abstracts. PLoS Med. 2013;10(4):1-8. doi:10.1371/ journal.pmed.1001419 